\title{
Emergency treatment of decompensated aortic stenosis
}

\author{
Dario Bongiovanni, ${ }^{1,2}$ Constantin Kühl, ${ }^{3,4}$ Sabine Bleiziffer, ${ }^{5}$ Lynne Stecher, ${ }^{6}$ Felix Poch, ${ }^{1}$ \\ Martin Greif, ${ }^{7}$ Julinda Mehilli, ${ }^{7}$ Steffen Massberg, ${ }^{7}$ Norbert Frey, ${ }_{1}^{3,4}$ Rüdiger Lange, ${ }^{5}$ \\ Karl-Ludwig Laugwitz, ${ }^{1,2}$ Gerhard Schymik, ${ }^{8}$ Derk Frank, ${ }^{3,4}$ Christian Kupatt ${ }^{1,2}$
}

\begin{abstract}
- Additional material is published online only. To view please visit the journal online (http://dx.doi.org/10.1136 heartjnl-2016-311037).
\end{abstract}

For numbered affiliations see end of article.

Correspondence to Professor Christian Kupatt, I. Medizinische Klinik und Poliklinik, Klinikum rechts der Isar, Ismaninger Straße 22, 81675 Munich, Germany; christian.kupatt@tum.de

DB and CK contributed equally.

Received 14 January 2017 Revised 24 April 2017 Accepted 25 April 2017 Published Online First 31 May 2017

\section{SLinked}

- http://dx.doi.org/10.1136/ heartjnl-2017-311706

\section{CrossMark}

To cite: Bongiovanni $D$, Kühl C, Bleiziffer $S$, et al. Heart 2018;104:23-29.

\section{ABSTRACT}

Objective The optimal treatment of patients with acute and severe decompensation of aortic stenosis is unclear due to recent advances in transcatheter interventions and supportive therapies. Our aim was to assess the early outcome of emergency transcatheter aortic valve implantation (eTAVI) versus emergency balloon aortic valvuloplasty (eBAV) followed by TAVI under elective circumstances.

Methods Emergency conditions were defined as: cardiogenic shock with requirement of catecholamine therapy, severe acute dyspnoea (NYHA IV), cardiac resuscitation or mechanic respiratory support. The data were collected according to the Valve Academic Research Consortium 2 (VARC-2) criteria.

Results In five German centres, 23 patients (logistic Euroscore $37.7 \% \pm 18.1$ ) underwent eTAVI and 118 patients underwent eBAV (logistic Euroscore $35.3 \% \pm 20.8)$. In the eTAVI group, immediate procedural mortality was $8.7 \%$, compared with $20.3 \%$ for the eBAV group ( $p=0.19$ ). After 30 days, cardiovascular mortality for the eTAVI group was $23.8 \%$ and for the eBAV group 33.0\% $(p=0.40)$. Analyses adjusting for potential confounders did not provide evidence of a difference between groups. Of note, the elective TAVI performed after eBAV ( $n=32$, logistic Euroscore 25.9\% \pm 13.9 ) displayed an immediate procedural mortality of $9.4 \%$ and a cardiovascular mortality after 30 days of $15.6 \%$. Major vascular complications were significantly more likely to occur after eTAVI $(p=0.01)$ as well as stroke $(p=0.01)$.

Conclusion In this multicentre cohort, immediate procedural and 30-day mortality of eTAVI and eBAV were high, and mortality of secondary TAVI subsequent to eBAV was higher than expected. Randomised study data are required to define the role of emergency TAVI in tertiary care centres with current device generations.

\section{INTRODUCTION}

Decompensated aortic valvular stenosis is a condition characterised by high mortality if treated medically and a significantly increased risk of perioperative mortality and morbidity in case of surgical aortic valve replacement. ${ }^{1}$ Catheter-based procedures such as emergency balloon valvuloplasty (eBAV) and emergency transcatheter aortic valve implantation (eTAVI) have considerably enlarged the therapeutic armamentarium. However, the optimal treatment strategy of severely decompensated patients with aortic stenosis is unknown.
Before the availability of TAVI, severely decompensated patients with aortic stenosis oftentimes were treated with $\mathrm{eBAV}^{2}$ This procedure offers an immediate reduction of the transvalvular gradient which, however, returns in a high percentage of patients to a relevant degree within 6 months. Moreover, depending on the balloon size chosen, there is a relevant risk of postprocedural severe aortic regurgitation.

Over the last years, the advances of transcatheter valve replacement, in particular in terms of procedural safety and efficacy, opened the new approach to more instable and frail patients. ${ }^{4}$ The use of biomarkers such as troponin $\mathrm{T}$ has allowed early risk stratification of patients with aortic stenosis. ${ }^{5}$ TAVI is becoming an appealing solution in elective patients, or following eBAV, and as 'stand-alone emergency' procedure of decompensated patients. However, unstable patients requiring inotropic therapy have been excluded from the most relevant clinical trials. ${ }^{67}$ TAVI requires larger sheath size (14-16 instead 8 French) and longer procedure time, possibly increasing the peri-interventional risks. Currently, data comparing the different available invasive treatment strategies in acutely decompensated patients are scarce. Therefore, the question of superiority of either a one-step emergency TAVI or a two-step approach involving BAV and subsequent TAVI has been considered in our multicentre retrospective cohort study. The aim of this study was to assess the early outcome of eTAVI and of eBAV followed by TAVI under elective circumstances as well as to generate first data and novel hypothesis to guide future prospective clinical trials.

\section{METHODS}

\section{Definitions and outcomes}

Emergency condition was defined as: severe decompensation (NYHA IV) with pulmonary oedema or cardiogenic shock requiring catecholamine therapy, cardiac resuscitation or mechanical respiratory support.

Our primary endpoints were the periprocedural and 30-day survival rate. Cardiovascular mortality was defined according to VARC-2 criteria. ${ }^{8}$ Secondary endpoints were the procedure-related complications according to VARC-2 criteria. Stroke was defined as an acute episode of focal or global neurological dysfunction confirmed by CT scan imaging, whereas transient ischaemic attack (TIA) was defined as a transient episode of 


\section{Multicenter retrospective cohort study}

\section{Acute severe cardiac decompensation due to critical valvular aortic stenosis}

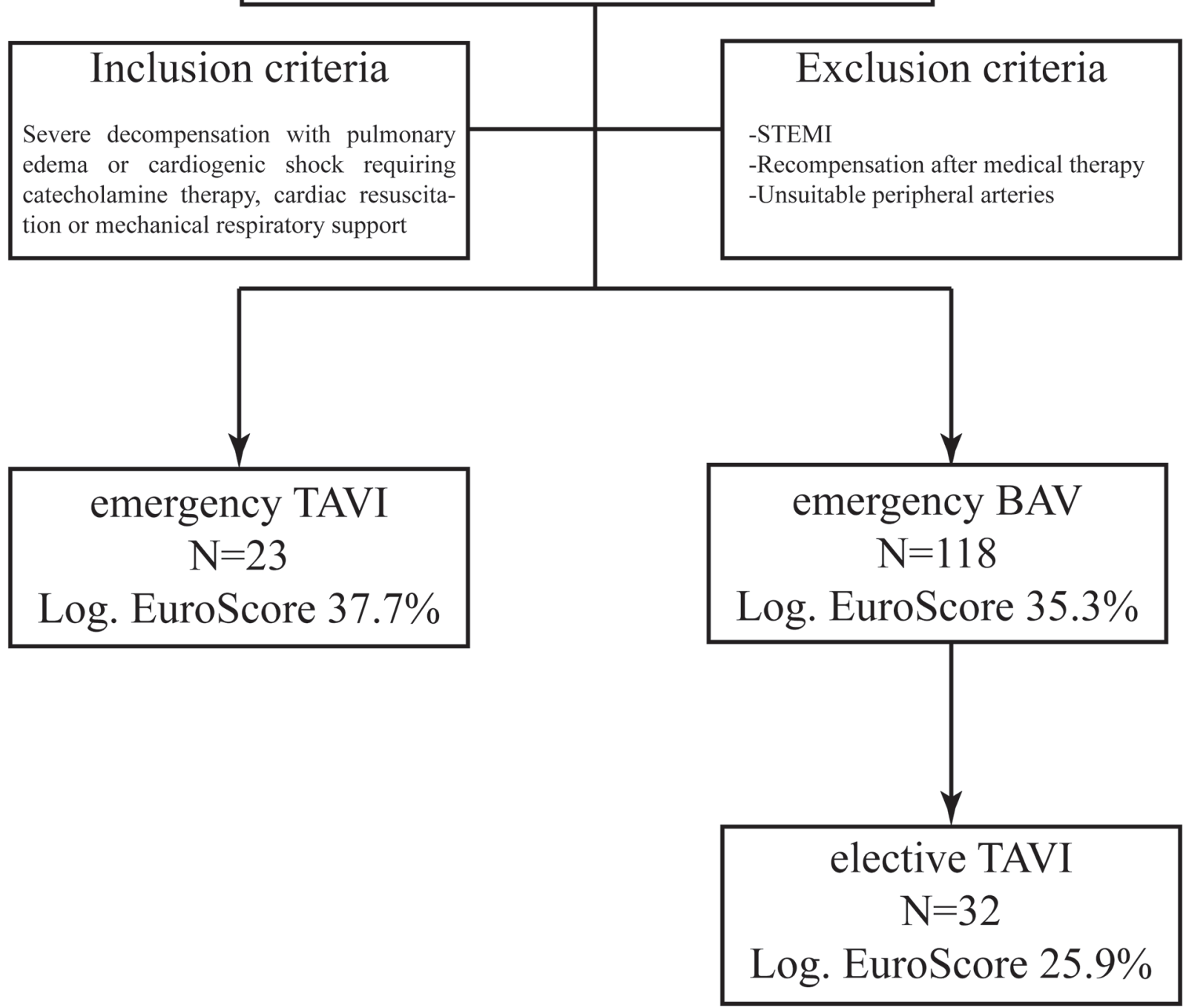

Figure 1 This figure shows the design of the multicentre cohort study. BAV, balloon valvuloplasty; TAVI, transcatheter aortic valve implantation, STEMI, ST elevation myocardial infarction.

focal neurological dysfunction caused by ischaemia, without acute infarction and with the absence of CT scan signs. Myocardial infarction was defined as the occurrence of new ischaemic symptoms (eg, chest pain) or new ischaemic signs (eg, new ST segment changes) and elevated cardiac biomarkers. Vascular complication, bleeding and kidney injury were defined in accordance with the VARC-2 criteria.

\section{Patients}

The study patients have been screened from approximately 3000 patients, who underwent eBAV or eTAVI from 2009 to 2015 in five German centres (Deutsches Herzzentrum and Klinikum rechts der Isar, Munich, Klinikum Großhadern, Städtisches Klinikum Karlsruhe and Universitätsklinikum
Schleswig-Holstein, Kiel). A total of 141 patients complying the given definition of emergency condition have been included in this study. Patients with unsuitable femoral arteries or unsuitable anatomy for TAVI were not included. All the procedures included in this study have been performed via transfemoral access. We conducted the study in accordance with the Declaration of Helsinki, and the study was approved by the local ethics committees. Due to the retrospective and anonymised nature of the study, a need for written informed consent was waived by the ethics committees.

\section{TAVI and BAV procedures}

Due to a lack of valid guidelines under emergency circumstances, the decision to treat the patients with eBAV or with eTAVI were 
Table 1 Baseline characteristics of study population

\begin{tabular}{|c|c|c|c|}
\hline & $\begin{array}{l}\text { eTAVI } \\
\mathrm{n}=23\end{array}$ & $\begin{array}{l}\text { eBAV } \\
n=118\end{array}$ & $\begin{array}{l}\text { Elective TAVI after eBAV } \\
\mathrm{n}=32\end{array}$ \\
\hline Age & $76.0 \pm 11.4$ & $81.3 \pm 7.6$ & $81.2 \pm 6.2$ \\
\hline Male & $\begin{array}{l}82.6 \% \\
19 / 23\end{array}$ & $\begin{array}{l}55.9 \% \\
66 / 118\end{array}$ & $\begin{array}{l}46.9 \% \\
15 / 32\end{array}$ \\
\hline Logistic Euroscore \% & $37.7 \pm 18.1$ & $35.3 \pm 20.8$ & $25.9 \pm 13.9$ \\
\hline Coronary artery disease & $\begin{array}{l}65.2 \% \\
15 / 23\end{array}$ & $\begin{array}{l}64.3 \% \\
74 / 115\end{array}$ & $\begin{array}{l}59.4 \% \\
19 / 32\end{array}$ \\
\hline One-vessel disease & $\begin{array}{l}21.7 \% \\
5 / 23\end{array}$ & $\begin{array}{l}12.2 \% \\
14 / 115\end{array}$ & $\begin{array}{l}12.5 \% \\
4 / 32\end{array}$ \\
\hline Two-vessel disease & $\begin{array}{l}17.4 \% \\
4 / 23\end{array}$ & $\begin{array}{l}20.9 \% \\
24 / 115\end{array}$ & $\begin{array}{l}21.9 \% \\
7 / 32\end{array}$ \\
\hline Three-vessel disease & $\begin{array}{l}26.1 \% \\
6 / 23\end{array}$ & $\begin{array}{l}31.3 \% \\
36 / 115\end{array}$ & $\begin{array}{l}25.0 \% \\
8 / 32\end{array}$ \\
\hline $\mathrm{PCl}$ in the last 30 days & $\begin{array}{l}13.0 \% \\
3 / 23\end{array}$ & $\begin{array}{l}21.7 \% \\
25 / 115\end{array}$ & $\begin{array}{l}12.5 \% \\
4 / 32\end{array}$ \\
\hline Previous $\mathrm{PCl}$ (>30 days) & $\begin{array}{l}17.4 \% \\
4 / 23\end{array}$ & $\begin{array}{l}16.5 \% \\
19 / 115\end{array}$ & $\begin{array}{l}21.9 \% \\
7 / 32\end{array}$ \\
\hline Previous CABG & $\begin{array}{l}8.7 \% \\
2 / 23\end{array}$ & $\begin{array}{l}13.0 \% \\
15 / 115\end{array}$ & $\begin{array}{l}6.3 \% \\
2 / 32\end{array}$ \\
\hline Previous MI & $\begin{array}{l}17.4 \% \\
4 / 23\end{array}$ & $\begin{array}{l}42.2 \% \\
49 / 115\end{array}$ & $\begin{array}{l}37.5 \% \\
12 / 32\end{array}$ \\
\hline Atrial fibrillation & $\begin{array}{l}30.4 \% \\
7 / 23\end{array}$ & $\begin{array}{l}61.4 \% \\
54 / 88\end{array}$ & $\begin{array}{l}46.9 \% \\
15 / 32\end{array}$ \\
\hline Peripheral artery disease Fontaine $\geq 11$ & $\begin{array}{l}17.4 \% \\
4 / 23\end{array}$ & $\begin{array}{l}19.3 \% \\
17 / 88\end{array}$ & $\begin{array}{l}9.4 \% \\
3 / 32\end{array}$ \\
\hline Pacemaker before intervention & $\begin{array}{l}4.3 \% \\
1 / 23\end{array}$ & $\begin{array}{l}15.2 \% \\
16 / 105\end{array}$ & $\begin{array}{l}13.8 \% \\
4 / 29\end{array}$ \\
\hline Active malignancy & $\begin{array}{l}8.7 \% \\
2 / 23\end{array}$ & $\begin{array}{l}25.3 \% \\
20 / 79\end{array}$ & $\begin{array}{l}6.7 \% \\
2 / 30\end{array}$ \\
\hline Chronic pulmonary disease & $\begin{array}{l}21.7 \% \\
5 / 23\end{array}$ & $\begin{array}{l}16.4 \% \\
9 / 55\end{array}$ & $\begin{array}{l}6.5 \% \\
2 / 31\end{array}$ \\
\hline
\end{tabular}

eBAV, emergency balloon valvuloplasty; eTAVI, emergency transcatheter aortic valve implantation; TAVI, transcatheter aortic valve implantation.

made on a case-by-case basis under responsibility of the local heart team, consisting of expert interventional cardiologists and cardiothoracic surgeons. eBAV procedures were performed via femoral access using 8-French sheaths. Before placing the arterial sheath, femoral angiography was performed. UFH was given at the discretion of the internationalist during the procedure under ACT control. TAVI procedures were performed in catheterisation laboratory under local or systemic anaesthesia and fluoroscopic guidance alone. All patients without an indication for anticoagulation were pretreated with aspirin and clopidogrel before TAVI procedure. In presence of oral anticoagulation patients were treated adding a single antiplatelet agent (ie, aspirin or clopidogrel) at the discretion of the interventional team. Peri-TAVI anticoagulation consisted of weight-adjusted unfractionated heparin (UFH) at a target ACT value between 250 and $300 \mathrm{~s}$. After the procedure, antiplatelet therapy was applied according to department policies.

\section{Statistical analysis}

Statistical analysis was conducted using SPSS software package (V.23.0) and R V.3.1.3. The primary endpoints of periprocedural and 30-day mortality, all-cause and cardiovascular specific, were compared between eTAVI and eBAV, and eTAVI and elective TAVI using Pearson's $\chi^{2}$ tests. Logistic regression models were fit to adjust for potential confounding variables (logistic Euroscore, age, gender, atrial fibrillation, coronary artery disease and percutaneous coronary intervention in the 30 days preceding the emergency procedure). Overall survival following eTAVI and
eBAV was estimated using Kaplan-Meier (K-M) curves. These, and the subsequent survival analyses, were performed both with and without censoring at the time of the TAVI operation for BAV patients who later had an elective TAVI. HRs comparing the groups were estimated via univariable and multivariable Cox regression models adjusting for potential confounding variables (age, logistic Euroscore, atrial fibrillation, coronary artery disease and a PCI in the 30 days preceding the emergency procedure as well as for aortic regurgitation, mitral regurgitation and reanimation). Descriptive statistics for the baseline characteristics and further clinical outcomes are presented for each group. The continuous variables are expressed as the mean $\pm \mathrm{SD}$, and outcomes are compared using Student's t-test. The categorical data are expressed as numbers and percentages, and outcomes are compared using the Pearson's $\chi^{2}$ test or Fisher's exact test as appropriate.

\section{RESULTS}

A total of 141 patients have been included in this study (figure 1). Twenty-three underwent eTAVI, while 118 have been treated with eBAV. Notable differences were observed between the two emergency groups regarding the baseline characteristics for age $(76.0 \pm 11.4$ years for eTAVI vs $81.3 \pm 7.6$ years for eBAV), gender (82.6\% males for eTAVI vs 55.9\% males for eBAV), atrial fibrillation (30.4\% for eTAVI and 61.4\% for eBAV) and a previous history of myocardial infarction (17.4\% for eTAVI and $42.2 \%$ for eBAV) (table 1, online supplementary table 1). There was not a notable difference in terms of risk profile between eTAVI 


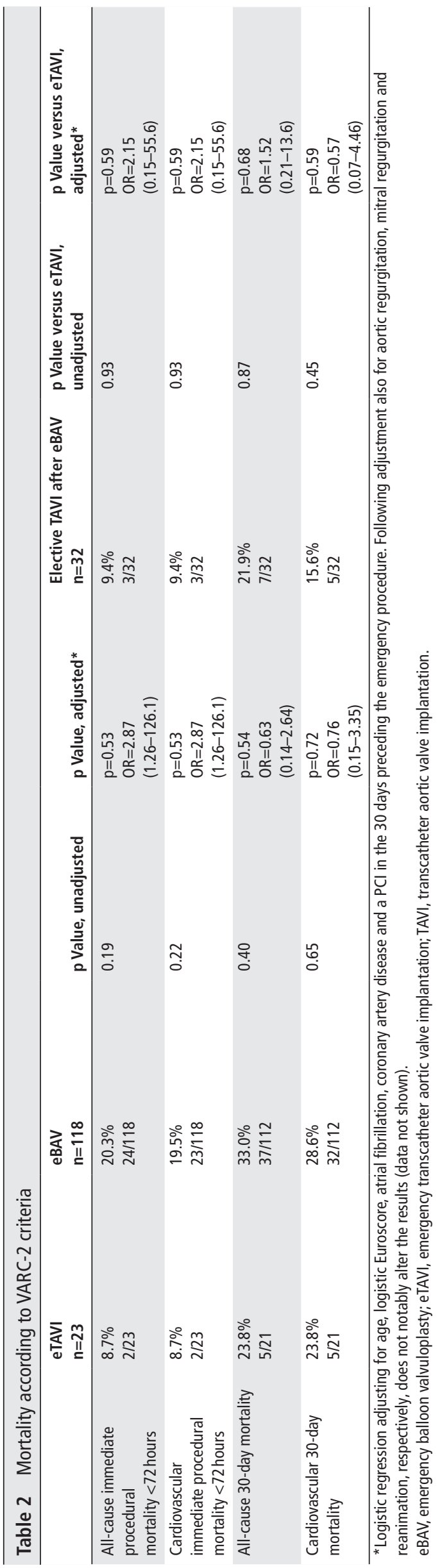

and eBAV groups (logistic Euroscore 37.7 \pm 18.1 for eTAVI and $35.3 \pm 20.8$ for eBAV). The periprocedural and 30 -day mortality are depicted in table 2. The eBAV group had an immediate periprocedural mortality of $20.3 \%$, while for eTAVI it was $8.7 \%$ $(\mathrm{p}=0.19)$. Similarly, the cardiovascular periprocedural mortality was $19.5 \%$ for the eBAV group and $8.7 \%$ for the eTAVI group $(p=0.22)$. Thirty days after the emergency procedures, the all-cause mortality was $33.0 \%$ and $23.8 \%$, respectively, for eBAV and for eTAVI $(\mathrm{p}=0.40)$, while the cardiovascular mortality was $28.6 \%$ for eBAV and $23.8 \%$ for eTAVI $(p=0.65)$. Adjusting for potential confounding factors with logistic regression, in the subset of patients with this data available, did not reveal any significance differences (table 2). The 30-day mortality rates stated previously included data from 15 patients who had elective TAVI within 30 days following eBAV, censoring these patients in the K-M analysis leads to similar 30-day mortality estimates of $31.9 \%$ for eBAV patients compared with $23.0 \%$ for eTAVI patients.

The eTAVI group suffered from major vascular complications at a rate of $21.7 \%$, significantly higher than after eBAV, with only $3.4 \%(\mathrm{p}=0.01)$ as well as from stroke $(8.7 \%$ vs $0 \%$, $\mathrm{p}=0.01$ ). No significant differences were observed with regard to minor bleeding $(8.7 \%$ for eTAVI vs $3.4 \%$ for $e B A V, p=0.56)$, major bleeding $(4.3 \%$ for eTAVI vs $12.9 \%$ for eBAV, $p=0.24)$ and life-threatening bleeding ( $4.3 \%$ for eTAVI vs $0.9 \%$ for eBAV, $\mathrm{p}=0.20$ ) (table 3). The rates of kidney injury and myocardial infarction did not display a significant difference between groups. Patients after eBAV had significant postprocedural aortic regurgitation (AR $\geq \mathrm{II})$ in $27.1 \%$, and in eTAVI only $4.3 \%(\mathrm{p}=0.02)$.

Among the patients treated with eBAV, 32 switched to elective TAVI after an average of 91 days (median: 35 days). This corresponds to $34.0 \%(32 / 94)$ of the eBAV patients without immediate procedural mortality. The logistic Euroscore of this group was lower compared with eTAVI (eBAV-TAVI $25.9 \% \pm 13.9$ vs eTAVI 37.7\% 18.1 . Except for age and gender, the other baseline characteristic did not notably differ compared with the eTAVI group (table 1). The all-cause and cardiovascular periprocedural mortality was $9.4 \%$ for the elective TAVI group. After 30 days, the all-cause mortality was $21.9 \%$, while the cardiovascular mortality was $15.6 \%$. These mortality rates were not significantly different if compared with the eTAVI group (table 2). No significant differences were observed between the emergency and the elective TAVI group concerning bleeding, vascular complication and kidney injury (table 3 ). In the elective TAVI group the rate of relevant aortic regurgitation (AR $\geq \mathrm{II})$ was $12.9 \%$, compared with the $4.3 \%$ in the eTAVI group $(\mathrm{p}=0.28)$.

In one case of eBAV, an extracorporeal life support system has been used periprocedurally. In the eTAVI group, the most frequent implanted prosthesis were the balloon-expandable Edwards valves (65.2\% of implanted valves), whereas in the elective TAVI group following the eBAV, the self-expandable Medtronic CoreValve was more frequently inserted $(50 \%$ vs $34.8 \%$ for balloon-expandable valves). However, the difference between distributions of valve types did not reach significance $(\mathrm{p}=0.32)($ table 4$)$.

The Kaplan-Meier curves estimating survival following eBAV and eTAV, with censoring at the time of elective TAVI, are shown in figure 2. The estimated HR comparing TAVI patients with BAV is $0.59(0.28 ; 1.25), \mathrm{p}=0.169$. The estimated HR is similar in the adjusted analysis $0.45(0.19,1.08), p=0.074$. Similar results were observed when patients with eBAV were not censored at the time of elective TAVI (see online supplementary figure 1). The survival analyses have also been adjusted, both with and without censoring at the time of the elective TAVI, 
Table 3 Clinical outcome according to VARC-2 criteria

\begin{tabular}{|c|c|c|c|c|c|}
\hline & $\begin{array}{l}\text { eTAVI } \\
\mathrm{n}=23\end{array}$ & $\begin{array}{l}\text { eBAV } \\
n=118\end{array}$ & $\mathrm{p}$ & $\begin{array}{l}\text { Elective TAVI after eBAV } \\
\mathrm{n}=32\end{array}$ & $\begin{array}{l}\text { p Value versus } \\
\text { eTAVI }\end{array}$ \\
\hline Bleeding & $\begin{array}{l}17.4 \% \\
4 / 23\end{array}$ & $\begin{array}{l}17.2 \% \\
20 / 116\end{array}$ & 0.98 & $\begin{array}{l}34.4 \% \\
11 / 32\end{array}$ & 0.16 \\
\hline Life threatening & $\begin{array}{l}4.3 \% \\
1 / 23\end{array}$ & $\begin{array}{l}0.9 \% \\
1 / 116\end{array}$ & 0.20 & $\begin{array}{l}3.1 \% \\
1 / 32\end{array}$ & 0.81 \\
\hline Major & $\begin{array}{l}4.3 \% \\
1 / 23\end{array}$ & $\begin{array}{l}12.9 \% \\
15 / 116\end{array}$ & 0.24 & $\begin{array}{l}21.9 \% \\
7 / 32\end{array}$ & 0.07 \\
\hline Minor & $\begin{array}{l}8.7 \% \\
2 / 23\end{array}$ & $\begin{array}{l}3.4 \% \\
4 / 116\end{array}$ & 0.56 & $\begin{array}{l}9.4 \% \\
3 / 32\end{array}$ & 0.93 \\
\hline Vascular complications & $\begin{array}{l}21.7 \% \\
5 / 23\end{array}$ & $\begin{array}{l}12.9 \% \\
15 / 116\end{array}$ & 0.27 & $\begin{array}{l}15.6 \% \\
5 / 32\end{array}$ & 0.56 \\
\hline Major & $\begin{array}{l}17.4 \% \\
4 / 23\end{array}$ & $\begin{array}{l}3.4 \% \\
4 / 116\end{array}$ & 0.01 & $\begin{array}{l}12.5 \% \\
4 / 32\end{array}$ & 0.61 \\
\hline Minor & $\begin{array}{l}4.3 \% \\
1 / 23\end{array}$ & $\begin{array}{l}9.5 \% \\
11 / 116\end{array}$ & 0.42 & $\begin{array}{l}3.1 \% \\
1 / 32\end{array}$ & 0.81 \\
\hline Myocardial infarction & $\begin{array}{l}0 \\
023\end{array}$ & $\begin{array}{l}4.4 \% \\
5 / 113\end{array}$ & 0.39 & $\begin{array}{l}3.1 \% \\
1 / 32\end{array}$ & 0.39 \\
\hline Stroke & $\begin{array}{l}8.7 \% \\
2 / 23\end{array}$ & $\begin{array}{l}0 \\
0 / 118\end{array}$ & 0.01 & $\begin{array}{l}6.3 \% \\
2 / 32\end{array}$ & 0.73 \\
\hline Pacemaker implantation & $\begin{array}{l}8.7 \% \\
2 / 23\end{array}$ & $\begin{array}{l}7.8 \% \\
4 / 51\end{array}$ & 0.51 & $\begin{array}{l}12.9 \% \\
4 / 32\end{array}$ & 0.62 \\
\hline Acute kidney injury & $\begin{array}{l}20.0 \% \\
3 / 15\end{array}$ & $\begin{array}{l}30.6 \% \\
26 / 85\end{array}$ & 0.41 & $\begin{array}{l}33.3 \% \\
9 / 27\end{array}$ & 0.36 \\
\hline Stage 1 & $\begin{array}{l}21.7 \% \\
5 / 23\end{array}$ & $\begin{array}{l}11.2 \% \\
10 / 89\end{array}$ & 0.06 & $\begin{array}{l}16.7 \% \\
5 / 30\end{array}$ & 0.07 \\
\hline Stage 2 & $\begin{array}{l}13.0 \% \\
3 / 23\end{array}$ & $\begin{array}{l}2.2 \% \\
2 / 89\end{array}$ & & $\begin{array}{l}0 \\
0 / 30\end{array}$ & \\
\hline Stage 3 & $\begin{array}{l}0 \\
0 / 23\end{array}$ & $\begin{array}{l}15.7 \% \\
14 / 89\end{array}$ & & $\begin{array}{l}13.3 \% \\
4 / 30\end{array}$ & \\
\hline Aortic regurgitation $\geq \mathrm{Il}$ (up to III) & $\begin{array}{l}4.3 \% \\
1 / 23\end{array}$ & $\begin{array}{l}27.1 \% \\
19 / 70\end{array}$ & 0.02 & $\begin{array}{l}12.9 \% \\
4 / 31\end{array}$ & 0.28 \\
\hline
\end{tabular}

eBAV, emergency balloon valvuloplasty; eTAVI, emergency transcatheter aortic valve implantation; TAVI, transcatheter aortic valve implantation.

for aortic regurgitation, mitral regurgitation and reanimation, respectively (see online supplementary table 2). Consistent with previous results, there is not statistically significant evidence of a difference following these adjustments.

\begin{tabular}{|c|c|c|c|}
\hline & $\begin{array}{l}\text { eTAVI } \\
\mathrm{n}=23\end{array}$ & $\begin{array}{l}\text { Elective TAVI after eBAV } \\
\mathrm{n}=32\end{array}$ & $\mathrm{p}$ Value \\
\hline \multicolumn{4}{|l|}{ Valve type } \\
\hline Self-expandable & $\begin{array}{l}34.8 \% \\
8 / 23\end{array}$ & $\begin{array}{l}50.0 \% \\
16 / 32\end{array}$ & 0.32 \\
\hline Balloon expandable & $\begin{array}{l}65.2 \% \\
15 / 23\end{array}$ & $\begin{array}{l}43.8 \% \\
14 / 32\end{array}$ & \\
\hline Lotus & $\begin{array}{l}0 \\
0 / 23\end{array}$ & $\begin{array}{l}6.3 \% \\
2 / 32\end{array}$ & \\
\hline \multicolumn{4}{|l|}{ Valve size } \\
\hline $23 \mathrm{~mm}$ & $\begin{array}{l}26.1 \% \\
6 / 23\end{array}$ & $\begin{array}{l}19.4 \% \\
6 / 31\end{array}$ & 0.38 \\
\hline $26 \mathrm{~mm}$ & $\begin{array}{l}45.5 \% \\
10 / 23\end{array}$ & $\begin{array}{l}61.3 \% \\
19 / 31\end{array}$ & \\
\hline $27 \mathrm{~mm}$ & $\begin{array}{l}0 \\
0 / 23\end{array}$ & $\begin{array}{l}3.2 \% \\
1 / 31\end{array}$ & \\
\hline $29 \mathrm{~mm}$ & $\begin{array}{l}21.7 \% \\
5 / 23\end{array}$ & $\begin{array}{l}16.1 \% \\
5 / 31\end{array}$ & \\
\hline $31 \mathrm{~mm}$ & $\begin{array}{l}8.7 \% \\
2 / 23\end{array}$ & $\begin{array}{l}0 \\
0 / 31\end{array}$ & \\
\hline
\end{tabular}

eBAV, emergency balloon valvuloplasty; eTAVI, emergency transcatheter aortic valve implantation; TAVI, transcatheter aortic valve implantation.

\section{DISCUSSION}

We conducted a retrospective cohort study including a total of 141 patients from five different tertiary centres aiming to collect a first set of data concerning the emergency treatment in severely decompensated patients secondary to severe aortic valve stenosis. We report that after 30 days, the all-cause mortality of eBAV was $33.0 \%$, with $28.6 \%$ attributed to cardiovascular deaths. Within the limitations of sample sizes and group differences, the 30-day mortality did not significantly differ from that of eTAVI $(23.8 \%)$. In this dataset carrying all limitations of a small retrospective study, we observed no statistical significant differences comparing eBAV and eTAVI but a non-significant trend in favour of eTAVI peri-interventionally ( $8.7 \%$ vs $20.3 \%$, $\mathrm{p}=0.29)$ as well as at 30 days $(23.8 \%$ vs $33.0 \%, \mathrm{p}=0.40)$. Of note, there was no difference between eTAVI and elective TAVI after eBAV. Moreover, we found no significant procedural differences by the 30-day VARC-2 criteria, ${ }^{9}$ except for a higher rate of major vascular complications and strokes in the eTAVI group. Obviously, cardiovascular 30-day mortality of our emergency cohorts exceeded that of elective TAVI in high-risk study group, amounting to $3.2 \%$ in Partner $A,{ }^{10}$ or $3.6 \%$ in the US CoreValve High risk study. In the large German Aortic Valve Registry (GARY) registry reflecting real-world conditions, inhouse mortality was $5.2 \% .{ }^{11}$ However, in the instance of aortic decompensation and shock, the prognosis worsens rapidly, amounting to $16 \%$ after more than one episode of pulmonary oedema ${ }^{12}$ and up to $33 \%$ in a recent study of 27 eTAVIs. ${ }^{13}$ Similarly, BAV, a procedure reportedly yielding $3.5 \%{ }^{14}$ to $6.5 \%{ }^{15} 30$-day mortality rates in 
elderly elective cases, rapidly progresses to $15 \%$ in a cohort with $7.5 \%$ shock patients ${ }^{16}$ or to ca. $20 \%$ with Society of Thoracic Surgeon (STS) scores of $20 \%{ }^{17}$ or a logistic Euroscore of $36 \%$. $^{18}$ In our series of 118 unstable patients, 30-day mortality further increased to $33 \%$ for eBAV.

Of note, several studies have used BAV as bridging procedure to TAVI or surgical valve replacement (SAVR). Again, mortality rates went along with predicted risk scores: whereas only one inhospital death was observed in 25 patients with a Euroscore below 20\%, ${ }^{19}$ and a $3 \%$ mortality at 30 days was reported in 33 patients with a logistic Euroscore of $35 \%,{ }^{20}$ it rose to $20 \%$, when $10 \%$ of patients were included with cardiogenic shock. ${ }^{18}$ A current retrospect analysis of 472 patients observed that the mortality rate of $55 \%$ at 6 months after BAV was halved in the cases undergoing TAVI $(n=65)$ or SAVR $(n=20) .^{16}$

Thus, given the published experiences, eBAV followed by elective TAVI seems a warranted approach. In this setting, the faster and deemed less invasive BAV is used as rescue procedure to stabilise the patient towards a TAVI procedure in more stable condition. Over the last years, the BAV strategy has been applied not only as bridge-to-TAVI but also as bridge-to-decision allowing to re-evaluate the patient in more stable settings. ${ }^{21}$ However, the recent developments of new generation transcatheter valve devices, requiring smaller sheaths and characterised by an improved safety profile and high efficacy allow TAVI to be also chosen in emergency settings. A 'stand-alone' emergency TAVI procedure, requiring only one exposure to contrast agents as well as to the bleeding and vascular complication risks, may be preferable than a two-step strategy (BAV as bridge to TAVI), though a slightly longer and more complex procedure. On the other hand, the emergency settings of acute decompensated

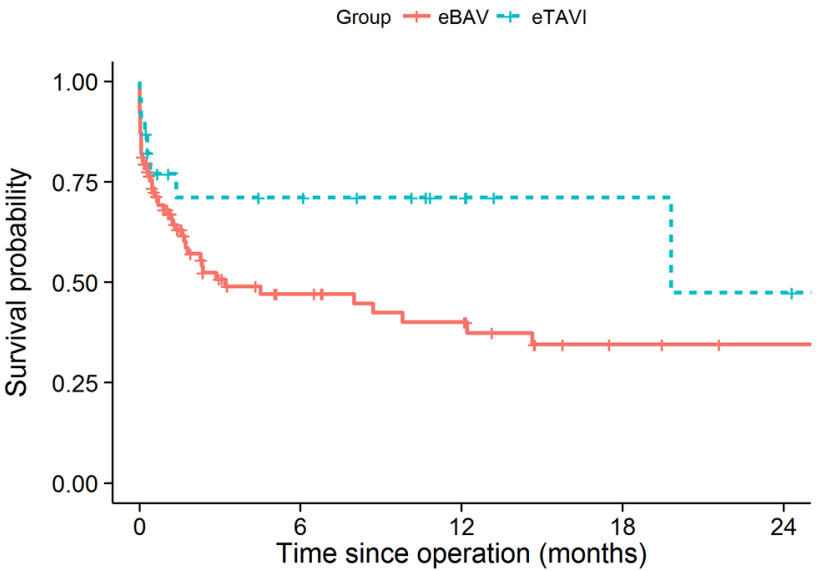

\begin{tabular}{|c|c|c|c|c|}
\hline \multirow{3}{*}{ 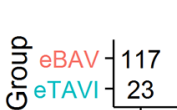 } & \multicolumn{3}{|c|}{ Number at risk by time } & \multirow{3}{*}{6} \\
\hline & 23 & 17 & 8 & \\
\hline & 11 & 6 & 3 & \\
\hline 0 & $\begin{array}{c}6 \\
\text { Tim }\end{array}$ & 12 & $\begin{array}{l}18 \\
\text { ths }\end{array}$ & 24 \\
\hline
\end{tabular}

Figure 2 Kaplan-Meier survival curves for eBAV and eTAVI patients (restricted to the first 2 years of follow-up). The eBAV patients with subsequent elective TAVI were censored at the time of TAVI intervention. Corresponding Cox models were fitted. The estimated HR comparing eTAVI patients with eBAV is $0.59(0.28 ; 1.25), p=0.169$. The estimated $\mathrm{HR}$ is comparable following adjustment for age, logistic Euroscore, atrial fibrillation, coronary artery disease and a $\mathrm{PCl}$ in the 30 days preceding the emergency procedure: $0.45(0.19,1.08), p=0.074$. eBAV, emergency balloon valvuloplasty; eTAVI, emergency transcatheter aortic valve implantation; TAVI, transcatheter aortic valve implantation. aortic stenosis did not always allow to perform a pre-TAVI CT in several cases. Performing TAVI without this information may increase the periprocedural risk.

Interestingly, the mortality rate of elective TAVI following eBAV was remarkably higher than expected. ${ }^{22} 23$ To our knowledge, there are no data available from the literature, comparing these two strategies. Despite the retrospective nature of this study and a lack of statistically significant differences in term of mortality between groups, our results point towards considering eTAVI as a viable, direct and effective strategy in a setting of acute decompensated aortic stenosis. However, we could observe at the Kaplan-Meier analysis a trend towards lower mortality (OR 0.55, p=0.172) between eTAVI and eBAV in favour for the first group (figure 2).

Our data are limited by the retrospective nature of our non-randomised study. Therefore, we cannot rule out the presence of a selection bias in our pool of patients. Patients with very high procedural risk may have been subjected to an eBAV procedure rather than an eTAVI. However, we could not detect differences between groups in terms of scores such as the logistic Euroscore (table 1), but groups did differ in characteristics such as age, gender and atrial fibrillation. Moreover, we performed eTAVI without preprocedural radiological diagnostic, such that a lack of time to collect a TAVI CT did not put a categorical stop sign to the eTAVI approach.

Another important limitation of this multicentric registry is that collected patient data comprise a time period where TAVI devices and sheaths underwent important improvements and operators were gaining experience. Moreover, due to the small number of patients, this study has low power to detect significant differences between the two groups. The sample size was further reduced when potential confounding variables were adjusted for in the analysis.

In summary, this retrospective analysis revealed a high 30-day mortality rate in both eBAV (33.0\%) and eTAVI procedures (23.8\%). A $21.9 \%$ mortality rate for elective TAVI after eBAV points to the vulnerability of this patient group, and renders primary eTAVI a viable therapeutic option. However, we observed in our set of data an unexpected high rate of cerebral events and vascular complication in the eTAVI group.

Taking in account the structural limits of this study, these data cannot clearly identify a superior strategy in emergency setting. However, this dataset represents the first multicentric retrospective analysis and highlights the need of a prospective randomised study in order to indicate the optimal treatment of cardiogenic shock due to acute aortic valvular stenosis in elderly high-risk patients.

\section{Author affiliations}

${ }^{1}$ I. Medizinische Klinik und Poliklinik, Klinikum rechts der Isar, Technical University of Munich, Munich, Germany

${ }^{2}$ DZHK (German Center for Cardiovascular Research), Partner Site Munich Heart Alliance, Munich, Germany

${ }^{3}$ Klinik für Innere Medizin III, Universitätsklinikum Schleswig-Holstein, Kiel, Germany ${ }^{4}$ DZHK (German Center for Cardiovascular Research), Partner Site Hamburg/Kiel/ Lübeck, Lübeck, Germany

${ }^{5}$ Clinic for Cardiovascular Surgery, German Heart Center Munich, Munich, Germany ${ }^{6}$ Institut für Medizinische Statistik und Epidemiologie, Technical University of Munich, Munich, Germany

${ }^{7}$ Medizinische Klinik und Poliklinik I, Klinikum Großhadern, LMU University, Munich, Germany

${ }^{8}$ Medizinische Klinik IV, Städtisches Klinikum Karlsruhe, Karlsruhe, Germany

Contributors DB collected, harmonised and analysed the data and wrote and submitted the manuscript. CK collected, analysed and interpreted the data and reviewed the manuscript. LS performed the statistical analysis. FP helped to collect the data. SB, MG, JM, SM, NF, RL, GS, DF and CK performed the balloon aortic 


\section{Key messages}

\section{What is already known on this subject?}

Despite the recent improvement of catheter-based aortic valve interventions, the treatment of acute decompensated aortic valvular stenosis in elderly high-risk patients still remains to be determined. To our knowledge, no data are available comparing different treatment strategies of cardiogenic shock due to acute aortic valvular stenosis.

\section{What might this study add?}

This is the first set of data comparing emergency transcatheter aortic valve implantation (eTAVI) to emergency balloon valvuloplasty (eBAV) as a bridge to TAVI in 141 elderly high-risk patients. In our multicentric retrospective analysis, we observed high immediate procedural mortality rate after both eBAV and eTAVI procedures (8.7\% in the eTAVI group, compared with $20.3 \%$ for the eBAV group, $\mathrm{p}=0.19$ ). After 30 days, cardiovascular mortality for the eTAVI group was $23.8 \%$ and for the eBAV group 33.0\%, which includes data from 15 patients who had elective TAVI in this time frame $(p=0.40)$. Analyses of overall survival, both with and without censoring at the time of the elective TAVI, and adjusting for possible confounding factors, also did not provide evidence of a difference between groups. Interestingly, the mortality rate of the elective TAVI following eBAV was remarkably higher than expected (immediate procedural mortality of $9.4 \%$ and a cardiovascular mortality after 30 days of $15.6 \%$ ).

\section{How might this impact on clinical practice?}

This dataset represents the first multicentric analysis and suggests emergency TAVI as a viable option in emergency settings. Moreover, this study highlights the need of a prospective randomised study in order to indicate the optimal treatment of acute cardiogenic shock due to severe aortic valvular stenosis.

valvuloplasty and transcatheter aortic valve implantation. K-LL reviewed and corrected the manuscript. CK planned and supervised the study, interpreted the results and wrote and revised the manuscript.

\section{Competing interests None declared.}

Ethics approval Ethics Committee, Klinikum rechts der Isar, Munich, Germany.

Provenance and peer review Not commissioned; externally peer reviewed.

Data sharing statement All the available data have been inserted in the Paper. There are not any other data available concerning this publication.

(C) Article author(s) (or their employer(s) unless otherwise stated in the text of the article) 2018. All rights reserved. No commercial use is permitted unless otherwise expressly granted.

\section{REFERENCES}

1 lung B, Baron G, Butchart EG, et al. A prospective survey of patients with valvular heart disease in Europe: the Euro Heart survey on valvular heart disease. Eur Heart J 2003:24:1231-43.
2 Cribier A, Savin T, Saoudi N, et al. Percutaneous transluminal valvuloplasty of acquired aortic stenosis in elderly patients: an alternative to valve replacement? Lancet 1986;1:63-7.

3 Otto CM, Mickel MC, Kennedy JW, et al. Three-year outcome after balloon aortic valvuloplasty. Insights into prognosis of valvular aortic stenosis. Circulation 1994;89:642-50.

4 Kodali SK, Williams MR, Smith CR, et al. Two-year outcomes after transcatheter or surgical aortic-valve replacement. N Engl J Med 2012;366:1686-95.

5 Frank D, Stark S, Lutz M, et al. Preprocedural high-sensitive troponin predicts survival after transcatheter aortic valve implantation (TAVI). Int J Cardiol 2013;169:e38-9.

6 Smith CR, Leon MB, Mack MJ, et al. Transcatheter versus surgical aortic-valve replacement in high-risk patients. N Engl J Med Overseas Ed 2011;364:2187-98.

7 Adams DH, Popma JJ, Reardon MJ. Transcatheter aortic-valve replacement with a selfexpanding prosthesis. N Engl J Med 2014;371:1790-8.

8 Kappetein AP, Head SJ, Généreux P, et al. Updated standardized endpoint definitions for transcatheter aortic valve implantation: the Valve Academic Research Consortium-2 consensus document (VARC-2). Eur J Cardiothorac Surg 2012;42:S45-60.

9 Kappetein AP, Head SJ, Généreux P, et al. Updated standardized endpoint definitions for transcatheter aortic valve implantation: the Valve Academic Research Consortium-2 consensus document. J Am Coll Cardiol 2012:60:1438-54.

10 Smith CR, Leon MB, Mack MJ, et al. Transcatheter versus surgical aortic-valve replacement in high-risk patients. N Engl J Med 2011;364:2187-98.

11 Walther T, Hamm CW, Schuler G, et al. Perioperative results and complications in 15,964 transcatheter aortic valve replacements: prospective data from the GARY registry. J Am Coll Cardiol 2015;65:2173-80.

12 Furuta $\mathrm{A}$, Lellouche $\mathrm{N}$, Mouillet $\mathrm{G}$, et al. Impact of previous acute pulmonary oedema after transcatheter aortic valve implantation: Insight from French Aortic National CoreValve and Edwards 2 [FRANCE 2]registry. Int I Cardiol 2015; 183:98-104

13 Frerker C, Schewel J, Schlüter M, et al. Emergency transcatheter aortic valve replacement in patients with cardiogenic shock due to acutely decompensated aortic stenosis. Eurolntervention 2016:11:1530-6.

14 Bordoni B, Moretti C, Marrozzini C, et al. Repeated aortic balloon valvuloplasty in elderly patients with aortic stenosis who are not candidates for definitive treatment. J Invasive Cardiol 2015;27:E277-84.

15 Moretti C, Chandran S, Vervueren PL, et al. Outcomes of patients undergoing balloon aortic valvuloplasty in the TAVI era: a multicenter registry. J Invasive Cardiol 2015:27:547-53.

16 Ben-Dor I, Maluenda G, Dvir D, et al. Balloon aortic valvuloplasty for severe aortic stenosis as a bridge to transcatheter/surgical aortic valve replacement. Catheter Cardiovasc Interv 2013;82:632-7.

17 Araque JC, Greason KL, Suri RM, et al. The role of balloon aortic valvuloplasty in patients with aortic valve stenosis and society of thoracic surgeons risk of $15 \%$ or higher. Ann Thorac Surg 2016;101:592-8.

18 Kamperidis V, Hadjimiltiades S, Mouratoglou SA, et al. Aortic balloon valvuloplasty before transcatheter valve replacement in high-risk patients with aortic stenosis. Herz 2016:41:144-50

19 Doguet F, Godin M, Lebreton G, et al. Aortic valve replacement after percutaneous valvuloplasty-an approach in otherwise inoperable patients. Eur J Cardiothorac Surg 2010;38:394-9.

20 Malkin CJ, Judd J, Chew DP, et al. Balloon aortic valvuloplasty to bridge and triage patients in the era of trans-catheter aortic valve implantation. Catheter Cardiovasc Interv 2013:81:358-63.

21 Saia F, Moretti C, Dall'Ara G, et al. Balloon aortic valvuloplasty as a bridge-to-decision in high risk patients with aortic stenosis: a new paradigm for the heart team decision making. J Geriatr Cardiol 2016;13:475-82.

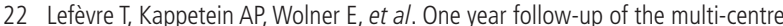
European PARTNER transcatheter heart valve study. Eur Heart J 2011;32:148-57.

23 Linke A, Wenaweser $P$, Gerckens $U$, et al. Treatment of aortic stenosis with a selfexpanding transcatheter valve: the International Multi-centre ADVANCE Study. Eur Heart J 2014:35:2672-84 